\title{
\Ј
}

\section{As gravações históricas da canção "Desafinado": desdobramentos da bossa nova no cenário internacional}

\author{
Liliana Harb Bollos \\ Universidade Federal de Goiás, Brasil \\ contato@lilianabollos.com.br \\ Fernando A. de A. Corrêa \\ Faculdade Santa Marcelina, Brasil \\ fernandocorrea@uol.com.br \\ Carlos Henrique Costa \\ Universidade Federal de Goiás, Brasil \\ costacarlosh@yahoo.com.br
}

\section{Introdução}

Considerado o "divisor das águas" (Medaglia, 1960, p. 79) da música popular brasileira moderna, pela representatividade e importância que alcançou dentro do cenário musical brasileiro nos anos subsequentes, o LP Chega de saudade (1959, Odeon, 3073) de João Gilberto foi lançado em 1959 e em pouco tempo obteve repercussão de crítica e público. O musicólogo Brasil Rocha Brito publicou um importante estudo sobre a bossa nova em 1960, afirmando que "nunca antes um acontecimento ocorrido no âmbito de nossa música popular trouxera tal acirramento de controvérsias e polêmicas" (Brito, 1960, p. 17). Antes desse disco, porém, em fevereiro de 1958, João Gilberto fez uma participação no LP Canção do Amor Demais (Festa, FT 1801) da cantora Elizete Cardoso, avaliado como uma espécie de disco de apresentação da bossa nova (Bollos, 2010), com músicas de Vinicius de Moraes e Antônio Carlos Jobim e arranjos desse último.

No disco ele interpretou ao violão duas faixas, "Chega de Saudade" (Jobim/Moraes) e "Outra vez" (Jobim), e a batida que simbolizaria a bossa nova foi gravada pela primeira vez nesse disco de Elizete Cardoso. Isso provocou uma reação ime-

\footnotetext{
1 Uma primeira versão deste artigo foi publicada nos Anais do V Simpósio Internacional de Musicologia (Bollos, 2015), em que se discutiu duas versões de "Desafinado", a de Chega de Saudade e Jazz Samba e foi um desenvolvimento da disciplina Bossa Nova e Crítica ministrada pela autora na Universidade Federal de Goiás, como parte de sua pesquisa de pós-doutorado com bolsa CAPES-PNPD.
} 
diata de músicos, críticos e também da gravadora Odeon, que instantaneamente convidou João Gilberto a gravar o seu primeiro single Chega de Saudade/Bim Bom (Odeon 12725/6) em julho de 1958. No final desse ano sairia o segundo single Desafinado/Hô-bá-lá-lá (Odeon, 13059) e finalmente em 1959 foi lançado Chega de Saudade, o primeiro LP de João Gilberto.

Em três anos João Gilberto lançou pela Odeon os discos Chega de saudade (1959), O amor, o sorriso e a flor (1960) e João Gilberto (1961), que para Zuza Homem de Mello (2001, p. 62) "formam uma trilogia de nível excepcional e se mantêm tão atuais como se tivessem sido gravados recentemente". Em pouco tempo o cantor baiano impôs um novo padrão estético à música popular brasileira, inventando e costurando ritmicamente um diálogo entre a voz e o violão, transformando o vioIão em instrumento participante do processo criativo, e não somente um "acompanhante" da voz, tão comum na época. Além disso, a batida que ele imprimiu, desde a sua primeira gravação no LP Canção do amor demais, foi decisiva para que muitos jovens se interessassem em tocar esse instrumento.

A Capitol lançou no mercado exterior no final de 1961 o disco O amor, o sorriso e a flor (Odeon, 1960) de João Gilberto com o título Brazil's Brilliant João Gilberto (Capitol T-10280) e, em abril de 1962, Stan Getz e Charlie Byrd lançam Jazz Samba (Verve, V6-8432), disco instrumental que abriu definitivamente o mercado internacional para a música brasileira. "Desafinado" recebe uma versão nesse disco com várias mudanças melódico-harmônicas com relação à versão original de João Gilberto. Nesse sentido, podemos perceber que é relativamente comum se encontrar diferentes versões de partituras de música popular:

Tal fato acontece porque, diferentemente da música erudita, que é baseada em partituras, portanto há uma tradição, há séculos, de manuseio, revisão, venda e direito autoral das obras, na música popular, esse fato é recente, por ser também intuitiva e improvisada. (Bollos, 2010, p. 141).

Chegamos à problemática de nossa pesquisa: podemos definir uma única versão como principal ou mesmo original na música popular? Os músicos norte-americanos ouviram a primeira gravação de "Desafinado" em Chega de Saudade e fizeram uma nova versão que foi difundida por todo o mundo. Este artigo é fruto de uma pesquisa documental qualitativa que discute diversas versões da canção "Desafinado", dentre elas a primeira gravação histórica no LP Chega de saudade (1959), a versão de Getz-Byrd em Jazz samba (1962), a gravação de Tom Jobim em seu 
disco de estreia como instrumentista em The composer of Desafinado plays (Verve, 1963), o disco Getz/Gilberto featuring A. C. Jobim (1963) e o projeto Sinatra/ Jobim, gravado em 1969, mas lançado somente em 1995 dentro da caixa The Complete Reprise Studio Recordings. Além disso, também compara harmônica e melodicamente as partituras da música nos livros Songbook Tom Jobim (Lumiar, 1994), Cancioneiro Jobim (Jobim Music, 2001), The Real Book (1971) e The New Real Book 1 (SHER, 1995). Qual foi o impacto das gravações supracitadas nas subsequentes gravações e partituras da canção em questão e quais foram os desdobramentos que ocorreram no cenário musical internacional?

\section{O cenário internacional da bossa nova}

Em 1960, segundo Ary Vasconcelos (1964, p. 28), os cantores Ella Fitzgerald e Paul Smith e o trompetista Roy Eldridge "ficaram entusiasmados com a bossa nova" durante uma temporada no Rio de Janeiro. Em 1961, outros músicos de jazz como Charlie Byrd, Zoot Sims, Al Cohn, Coleman Hawkins, Herbie Mann, Tony Bennett também tomaram conhecimento dessa música em solo brasileiro e Don Payne, por sua vez, contrabaixista de Tony Bennett, levou alguns discos de bossa nova para os EUA e lá mostrou ao seu vizinho, o saxofonista Stan Getz, segundo Zuza H. Mello (2001, p. 64). Gravado em fevereiro e lançado em abril de 1962, o LP Jazz Samba (Verve) vendeu, segundo Ruy Castro (2002, p. 327), um milhão de cópias naquele ano, sendo que a revista Billboard de 05 maio 1962 noticiou o lançamento do disco e ainda Stan Getz lançou o disco Big Band Bossa Nova, com a Big Band de Gary McFarland, ambos anteriores ao concerto do Carnegie Hall, em novembro.

Ainda em 1962, o saxofonista Coleman Hawkins gravou o LP Desafinado em setembro de 1962 e recebeu uma crítica de Harvey Pekar na revista Down Beat em 17 jan. 1963, considerado um álbum de bossa nova com música de alta qualidade. A primeira versão vocal em inglês da música foi feita por Pat Thomas no single Desafinado (Slightly out of Tune), pela Verve (VK-10269), com arranjo de Lalo Schifrin e produção de Creed Taylor. A revista Billboard Music Week de 29 set. 1962 (p. 33) fez anúncio do lançamento do disco da cantora de Chicago e no dia 20 out. 1962 (p. 58) citou que o disco tinha sido bem aceito e que Jazz Samba estava na 9a colocação. Logo em seguida a cantora Ella Fitzgerald gravou o single Desafinado (Slightly out of Tune, VK 10274), pela Verve, e a Billboard de 03 nov. 1962 comentou que a versão de Ella Fitzgerald havia sido lançada naquela 
semana. Já na revista Billboard Music Week de 15 dez. 1962, houve três menções a "Desafinado", 240 lugar a Getz e Byrd, a 780 posição à cantora Pat Thomas e a $102^{a}$ a Ella Fitzgerald.

Aos poucos, foi-se delineando a possibilidade de se fazer um concerto com músicos brasileiros no Carnegie Hall, evidência do prestígio alcançado pela música brasileira. Com o título Bossa Nova - New Brazilian Jazz, o concerto no Carnegie Hall em Nova York em 21 nov. 1962 foi um marco para a música popular brasileira no exterior quando o público norte-americano entrou em contato com a bossa nova tocada por brasileiros, como João Gilberto, Tom Jobim, Luiz Bonfá, Roberto Menescal, Sérgio Mendes, entre outros músicos, já que, até àquela data, eles conheciam somente as versões dos músicos estrangeiros.

Sobre o sucesso da versão de "Desafinado" de Jazz Samba, o jornalista Flávio de Mattos afirma:

Em meados de 1962, Getz é convidado para escrever o tema musical da série Dr. Kildare, sucesso da tv americana. No lado B do compacto, Creed Taylor incluiu uma versão reduzida de Desafinado, com apenas dois minutos, que incluía o solo de saxofone de Getz e deixava de fora a guitarra de Charlie Byrd. Essa versão de Desafinado estourou as rádios dos Estados Unidos, tornando-se um fenômeno, que ia além das audiências de jazz. O single puxou as vendas do álbum Jazz Samba à marca de 1,6 milhão cópias. Em março de 1963 chegou ao primeiro lugar no ranking da Revista Billboard. (Mattos, 2016).

Júlio Hungria cita em crítica de 28 nov. 1962 para o jornal Correio da Manhã do Rio de Janeiro que "Desafinado" já tem mais de dez lançamentos, dentre eles: Stan Getz \& Charlie Byrd; Ella Fitzgerald; Llyd Mayer; Pat Thomas; Freda Payne; Bob Gallo; Contrasts e Julie London; Mavis Rivers e Laurindo de Almeida.

Em março de 1963 Stan Getz produziu outro disco de bossa nova, Getz/Gilberto featuring A. C. Jobim, desta vez somente com músicos brasileiros, entre eles João Gilberto, Tom Jobim, Sebastião Neto, Milton Banana e Astrud Gilberto, que alcançou grande sucesso de vendas como também de crítica, tendo vencido inclusive vários prêmios Grammy, entre os quais o de melhor disco, melhor canção para "Garota de Ipanema" (Jobim/Moraes) e melhor intérprete para João Gilberto. 
No final de 1963 Antônio Carlos Jobim lança pela Verve Records o seu primeiro LP, The composer of Desafinado plays, um disco instrumental com arranjos de Claus Ogerman, tendo recebido boas críticas sobre esse trabalho e, em 1967, Frank Sinatra gravaria com Jobim o LP Francis Albert Sinatra \& Antonio Carlos Jobim, marcando, definitivamente, a música brasileira internacionalmente.

Dentro do jazz e posteriormente na música popular em geral popularizaram-se partituras com melodias e cifras (lead sheets) cuja compilação em livro recebeu o nome inicialmente de Fake book a partir dos anos 1940. Posteriormente, com partituras mais bem elaboradas e revisadas, o primeiro livro no formato Real Book ${ }^{2}$ foi desenvolvido dentro da Berklee School of Music em Boston (EUA) num trabalho conjunto de professores e alunos, tendo sido impulsionado inicialmente pelo pianista Paul Bley, baixista Steve Swallow e seus alunos, com a tarefa de transcrever músicas para o livro. Nessa versão manuscrita e ainda sem direitos autorais do Real Book (1971), a partitura de "Desafinado" está com quatro compassos a menos, além de modificações melódico-harmônicas que aqui citaremos.

No Brasil esse formato de partitura popularizou-se através dos songbooks produzidos por Almir Chediak pela Editora Lumiar a partir de 1987, sendo que a versão de "Desafinado" no Songbook Tom Jobim (1994) e mais recentemente no Cancioneiro Jobim (Jobim Music, 2001) são muito parecidas com a gravação de João Gilberto de 1959. Já as partituras do Real Book manuscrito (1971) e The New Real Book (1995) possuem modificações melódico-harmônicas, assim como supressão de compassos. A esse respeito, o próprio Tom Jobim declarou, em entrevista: "O que eu acho lamentável, no caso dos editores, é eles terem editado as minhas músicas todas erradas. Isso é que me chateia. E vai para o mundo inteiro! Isso é que é um desastre" (Jobim, 1994, p. 14). E, ao ser indagado em qual projeto estava envolvido, Jobim enfaticamente respondeu: "Um dos trabalhos que estou fazendo é a revisão da minha própria obra, porque os editores erraram tudo. Erraram na melodia, na harmonia e no ritmo. E não adianta deixar tudo isso cheio de erros" (Jobim, 1994, p. 15). Ele se referia ao livro Cancioneiro Jobim, publicado em 2001.

\footnotetext{
2 O termo Real Book é genérico, pode referir-se a compilações de lead sheets para canções de jazz, mas também se refere ao primeiro volume de uma série de livros transcritos pelos estudantes e professores da Berklee College o Music nos anos 1970, citado por Gold e Vila (2012, p. 41-42) e Aurwin (2009).
} 


\title{
3. Explorando "Desafinado"
}

Se "Chega de saudade" foi o divisor de águas, "Desafinado" transformou-se na canção mais significativa do movimento bossa-novista, "verdadeiro manifesto", para Brasil Rocha (1960, p. 38). Por conta da letra dessa canção, João Gilberto foi considerado literalmente um cantor desafinado, para os mais desavisados. Na verdade, Jobim e Mendonça comentavam sobre cantores da noite que desafinavam e resolveram escrever um samba que parecesse uma defesa dos desafinados, mas tão complicado e cheio de alçapões dissonantes que, ao ser cantado por um deles, iria deixá-los em apuros (Castro, 1990, p. 205).

Sobre o nascimento da canção, Marcelo Câmara (2001, p. 47) afirma:

\begin{abstract}
Newton e Tom se divertiam muito no apartamento da Prudente de Morais. Faziam comentários críticos, de muita ironia e riso, sobre alguns cantores da noite carioca que desafinavam bravamente e que eles tiveram o "heroísmo" de acompanhar ao piano. O assunto já se tornara recorrente nas conversas de ambos. Mas, agora, as observações e os reparos tinham virado gozação. E tema de música, de um samba que os dois estavam compondo [...]. Seria, na verdade, uma homenagem e, ao mesmo tempo, uma arapuca para esses agressores ao bom ouvido musical. [...]

A princípio, para Newton e Tom, fazendo o turbulento e tradicional revezamento no teclado, o samba era uma brincadeira, uma sátira inteligente, bem-humorada. Não pensavam em gravação nem em mercado de discos. O negócio é que a obra foi se estruturando, se erguendo, música e letra simultaneamente... e quando se deram conta, a música estava pronta. "Ficou interessante" - atestaram.
\end{abstract}

Segundo Santuza Naves (2004, p. 84), a pretexto de falar de amor, os autores Jobim e Mendonça fazem comentários mutuamente, aludindo ao seu próprio processo de composição avesso às convenções musicais, exercitando a conciliação da linguagem acessível da cultura de massa ("fotografei você na minha rolleiflex"), com o efeito do "estranhamento" tão caro às vanguardas históricas do início do século XX. Naves afirma ainda que alguns músicos populares brasileiros já exercitavam uma postura crítica, mas a radicalizaram a partir da bossa nova. Na verdade, segundo Câmara (2001, p. 47), a inclusão da máquina fotográfica Rolleiflex na canção foi sugerida por Newton Mendonça, apaixonado por cinema e fotografia, que teria fotografado a esposa com o filho no colo com essa câmera na ocasião. Além disso, a canção é bastante atípica, com harmonia densa, difícil, com duas grandes modulações, e a melodia é composta de intervalos difíceis de entoar, justamente para um cantor amador não conseguir cantar. 
A parceria entre Newton Mendonça e Tom Jobim rendeu dezessete canções, entre as quais "Desafinado", "Meditação", "Samba de uma nota só", Caminhos Cruzados" e "Discussão". Apesar de Jobim ter ficado conhecido como o compositor da dupla, ele afirmou que tanto ele quanto Mendonça escreviam letra e música: "A gente ia trabalhando junto a parte musical. Era tudo misturado. Ele ficava com o lápis e o caderno, e eu sentado ao piano. A gente fazia tudo junto. Era diferente do que faço, por exemplo, com o Chico Buarque" (Jobim, 1994, p. 12). Mendonça faleceu em 1960 aos 33 anos e não presenciou o sucesso de suas músicas e, segundo Tárik de Souza (2003, p. 191), teve sua obra subavaliada. Um descuido da produção do single Desafinado (Mendonça/ Jobim) e Ho-ba-la-lá (João Gilberto) também favoreceu o pouco reconhecimento de Mendonça, como conta Câmara:

Absurdamente, no centro do disco 78 [rpm] lançado por João Gilberto (Odeon Rio 13094-14426), estava escrito: "DESAFINADO (Antonio Carlos Jobim)". Foi omitido o nome de Newton. Uma segunda tiragem incluiu o nome do parceiro, mas de forma incorreta: "DESAFINADO (Antonio Carlos Jobim - Milton Mendonça)". (Câmara, 2001, p. 48).

Pode-se talvez entender o fato de Newton Mendonça ser menos lembrado pela mídia e público por conta de seu falecimento tão precoce e também por não constar seu nome como autor junto à música "Desafinado". Por outro lado, o compositor Carlos Lyra, citado por Câmara, explica como é a questão do direito autoral de músicas de vários autores no Brasil e como foi a parceria Jobim-Mendonça:

Parceria autêntica. Newton Mendonça é um parceiro autêntico de Tom Jobim. Por "parceria autêntica", uma expressão antiga, entende-se aquela onde os autores participam, igualmente, de música e letra. [...] É uma convenção internacional, pouco observada no Brasil, o sistema de apresentar os autores de uma obra musical de tal maneira que o nome do músico preceda o nome do letrista. No caso da parceria autêntica, por exemplo, entre Newton Mendonça e Tom Jobim, fica o impasse de qual nome deve preceder o outro, o autor da música (Lyra apud Câmara, 2001, p. 84).

Depois do reconhecimento internacional à música popular brasileira e sua ampla divulgação após o concerto do Carnegie Hall, Jobim percebe a necessidade de resguardar o direito autoral de suas músicas e viaja para os Estados Unidos, cuja viagem é comentada por Vinicius de Moraes em sua coluna "Bossa Nova" para o Diário Carioca de 12 nov. 1964 na resenha "Em tom bem triste":

Parte hoje para os Estados Unidos o meu querido amigo e parceiro Antônio Carlos Jobim. Sua missão, não conheço mais bela: defender o prestígio sempre crescente de nossa música popular, de que foi o motivador principal, através da lírica beleza de seus melhores 
sambas e canções. [...] Lá vai ele, no entanto, enfrentar a dureza e grossura dos editores americanos e a falta de sensibilidade dos letristas profissionais no sentido de preservar a verdade de suas canções. [...] Há três dias atrás eu o vi levantar um empréstimo para poder viajar. [...] Mas isso não constitui um problema, pois o dinheiro chegará, fora de dúvida. Suas canções são, neste momento mesmo em que escrevo estas linhas, executadas centenas de vezes na Europa, nos Estados Unidos e aqui, no nosso Continente. [...] Você está trazendo mais prestígio e divisas para o Brasil. (Moraes, 1964, p. 7).

Uma década mais tarde desta afirmação de Vinicius de Moraes, os primeiros livros de partituras norte-americanos começam a ser divulgados, e a versão de "Desafinado" que lá aparece é a de Getz-Byrd, com diversas mudanças melódico-harmônicas, disseminando no meio musical essa versão dos norte-americanos. Nem mesmo a bela versão de Getz/Gilberto com participação de Jobim foi levada em conta.

A estrutura de "Desafinado" está escrita no formato AABA, porém o número de compassos é bastante distinto do clássico formato de 32 compassos com oito compassos para cada parte, como podemos notar em músicas como "Só danço samba" (Jobim) e "Take the "A" train" (Ellington/ Strayhorn), entre muitas canções populares. Em todas as cinco gravações de "Desafinado" aqui citadas, o número de compassos para a forma AABA é de 68 compassos, sendo que optamos por identificar e numerar as partes que compõem a forma da música em A1 (16 compassos), A2 (16 compassos), B (16 compassos) e A3 (20 compassos) pois, apesar das partes $A, A 1$ e $A 2$ conterem o mesmo motivo, elas são muito diversas entre si, diferentemente do clássico formato em que existem diferenças melódico-harmônicas somente nos dois compassos finais da parte $A$.

\subsection{Comparações entre as versões de "Desafinado"}

Dentre as gravações analisadas, as versões de "Desafinado" de Chega de saudade, Sinatra/Jobim e The composer of Desafinado plays estão na tonalidade Mi maior, a de Getz/Gilberto featuring A. C. Jobim está em Mi bemol e a de Jazz samba, assim como todos os livros, estão em Fá maior, de modo que se optou aqui por determinar a tonalidade Fá para facilitar a comparação das versões.

Essa canção possui uma introdução (Figura 1), também chamada de verso, transcrita no Cancioneiro Jobim e gravada por poucos músicos, entre os quais destacamos os discos de Tom Jobim The composer of Desafinado plays (1963), Terra brasilis (1980), Inédito disco 2 (1987), Sinatra/Jobim (1995), Minas ao vivo piano e 
voz (2004) e os discos Você ainda não ouviu nada (Philips, 1964) de Sérgio Mendes \& Bossa Rio e Ella abraça Jobim (Pablo Records, 1981) da cantora Ella Fitzgerald.

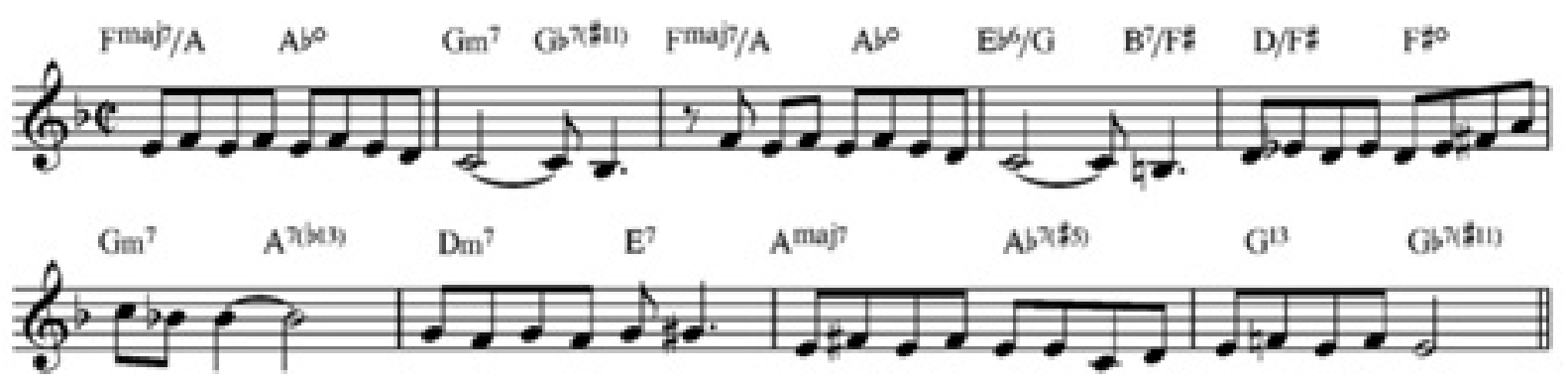

Figura 1: Introdução. "Desafinado". Cancioneiro Jobim.

Os dois últimos compassos da introdução se repetem durante o tema nos compassos 29-32 com a mesma sequência melódico-harmônica, porém, na versão Sinatra/Jobim, o cantor não repete no tema a mesma melodia do verso, como mostra a Figura 6.

Em seguida, comparamos as diferenças melódico-harmônicas que existem entre as versões com base nas partituras do Songbook Tom Jobim e Cancioneiro Jobim, de modo que consideramos como compasso 1 a partir da exposição do tema, dividindo a análise pela forma $A 1, A 2, B$ e $A 3$ :
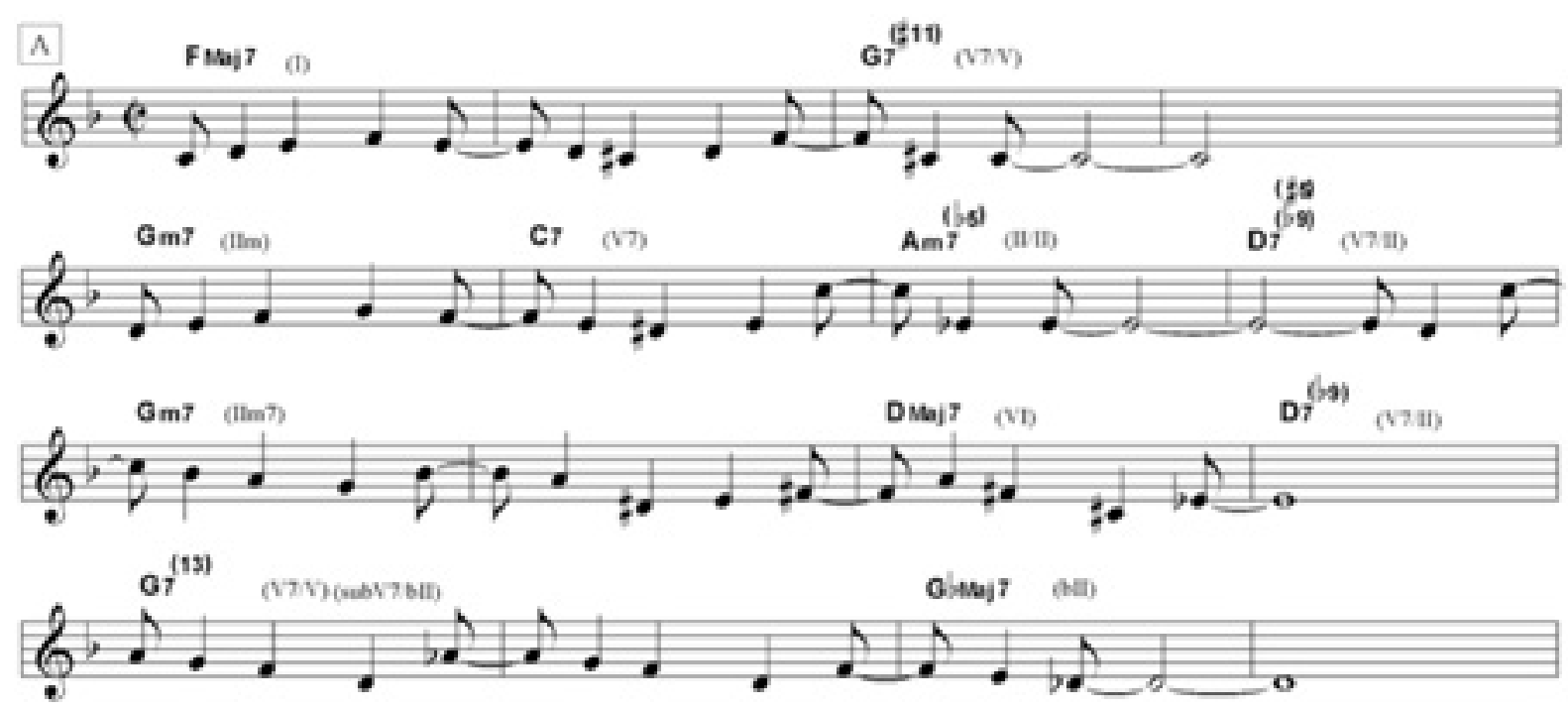

Figura 2: Cancioneiro Jobim, parte A1, c.1-16.

A relação melódico-harmônica de uma música determina situações de maior tensão, sofisticação ou mesmo dissonância e sua relação se dá quando o tempo forte da melodia repousa sobre uma nota harmônica muito expressiva, muitas vezes dissonante. Quando essa nota harmônica se apoia em graus acima das notas da 
tétrade (tônica, 30, 50 e 70), chamamos de tensões ou "graus altos", como 9, b9, \#9, \#11, 13, b13. Se determinada melodia possui um ou vários graus altos, é considerada mais sofisticada, incomum, inesperada. Em "Desafinado", no momento em que ele canta a primeira frase "se você disser que eu desafino, amor", a palavra amor carrega grande tensão, pois sua melodia se apoia no intervalo de quarta aumentada (Dó sustenido), ou \#110 do acorde de G7 (V7/V). No compasso 3, nos livros Songbook Tom Jobim e The Real Book (manuscrito e impresso), é grafada como a quinta diminuta (Ré bemol), como a Figura 3, mas grafamos como no Cancioneiro Jobim, com 11a aumentada (Dó sustenido), como a Figura 2. Para nós, é um acorde dominante com 11a aumentada, uma nota de tensão que se localiza acima da tétrade, que pode ser executado também com 9a maior e 13a maior, formando, assim, a escala lídia dominante ou Mixolídia \#11.

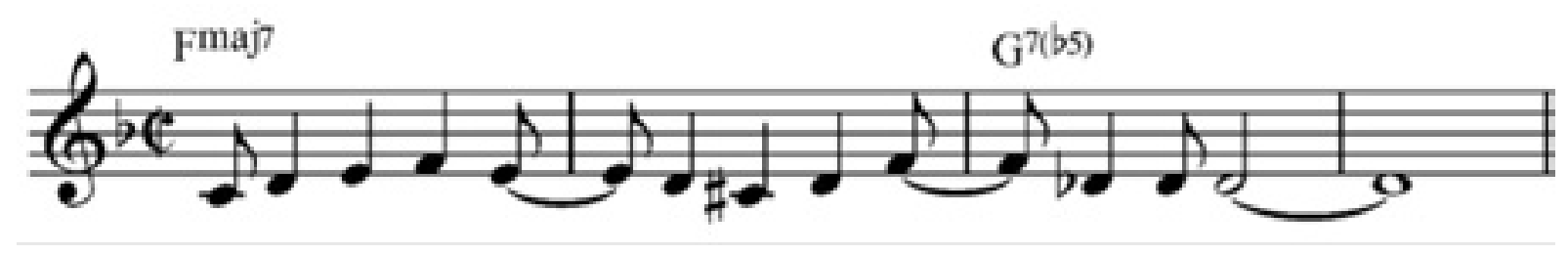

Figura 3: Songbook Tom Jobim, c. 1-4.

Segundo Gekas, o tratamento harmônico de "Desafinado" é caracterizado por acordes de superestrutura. Às tríades e tétrades são adicionadas nonas décimas primeiras e décimas terceiras. "Essas notas de tensão que muitas vezes são também notas melódicas, produzem uma textura caracterizada pela dissonância, seja no relacionamento entre cada nota do acorde ou entre linha melódica e linha do baixo" (Gekas, 2005, p. 94).

Na primeira parte (A1) encontramos diferenças rítmicas entre os dois songbooks de Jobim que não comprometem os aspectos melódico-harmônicos como nos $1^{\circ}$, $5^{\circ}$ e $13^{\circ}$ compassos. No Cancioneiro Jobim uma pausa de colcheia precede a melodia, e no Songbook Tom Jobim a melodia começa no primeiro tempo do compasso. Desse modo, este estudo não fará observações quanto aos aspectos rítmicos que constam nas várias versões.

Com relação à versão de "Desafinado" em Chega de saudade, João Gilberto executa ao violão alguns acordes que diferem dos songbooks, como nos compassos 8 , 
12 e 24, em que ele toca Lá diminuto $\left(A^{\text {dim }}\right)$ e na partitura consta $D^{(b 9)}$, Ré dominante, acorde dominante secundário do segundo grau ( $\mathrm{Gm})$. Esse acorde diminuto tem função dominante, o que significa que podemos substituir $D 7^{(b 9)}$ por $A^{\text {dim }}$ e a função dominante prevalece.

Já no compasso 11, a partitura do livro The New Real Book na Figura 4 grafa como acorde dominante, porém em nenhuma versão aparece o acorde $D^{7}$, mas $D^{7 M}$. No mesmo compasso na versão Jazz Samba a nota que precede o Mi bemol é um Ré (Figura 4), mas na versão original (Figura 2) é Dó sustenido.

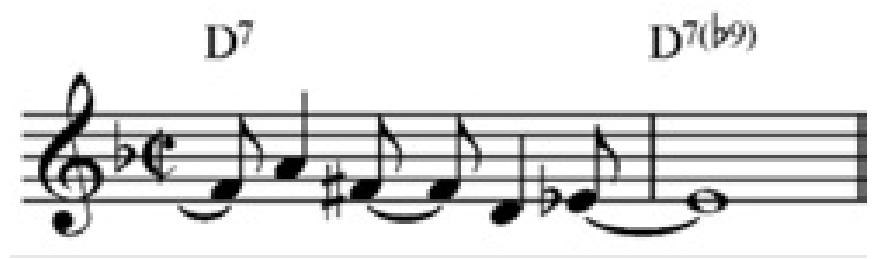

Figura 4: The New Real Book, c. 11-12.

No compasso 13 (Figura 5), encontramos em Jazz Samba uma diferença melódico-harmônica quando a nota Lá bemol aparece nos dois compassos, tendo como acompanhamento o acorde dominante $\mathrm{G}^{7(\mathrm{~b} 9)}$, enquanto que, na versão de João Gilberto e demais versões em que Jobim atua, no $13^{\circ}$ compasso a melodia é a nota Lá, o nono grau de $\mathrm{G}^{7(9)}$ e no compasso posterior é Lá bemol, a nona menor de $\mathrm{G}^{7(\mathrm{~b} 9)}$.

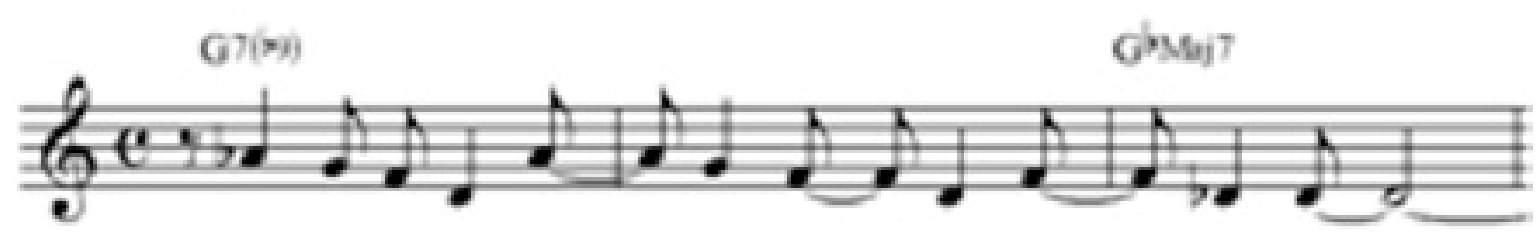

Figura 5: Jazz Samba, c. 13-15

Ainda na Figura 5, no compasso 15, em Jazz samba a nota Ré bemol é repetida, enquanto que, na versão original na Figura 2, temos as notas Mi e Ré bemol. Como a versão da Figura 5, temos as gravações de Ella Fitzgerald, de Pat Thomas e os realbooks. Em seguida, nos compassos 17-32, em que chamamos $A 2$, há uma nova exposição do tema com desenvolvimento, preparando para a modulação na parte $\mathrm{B}$ : 


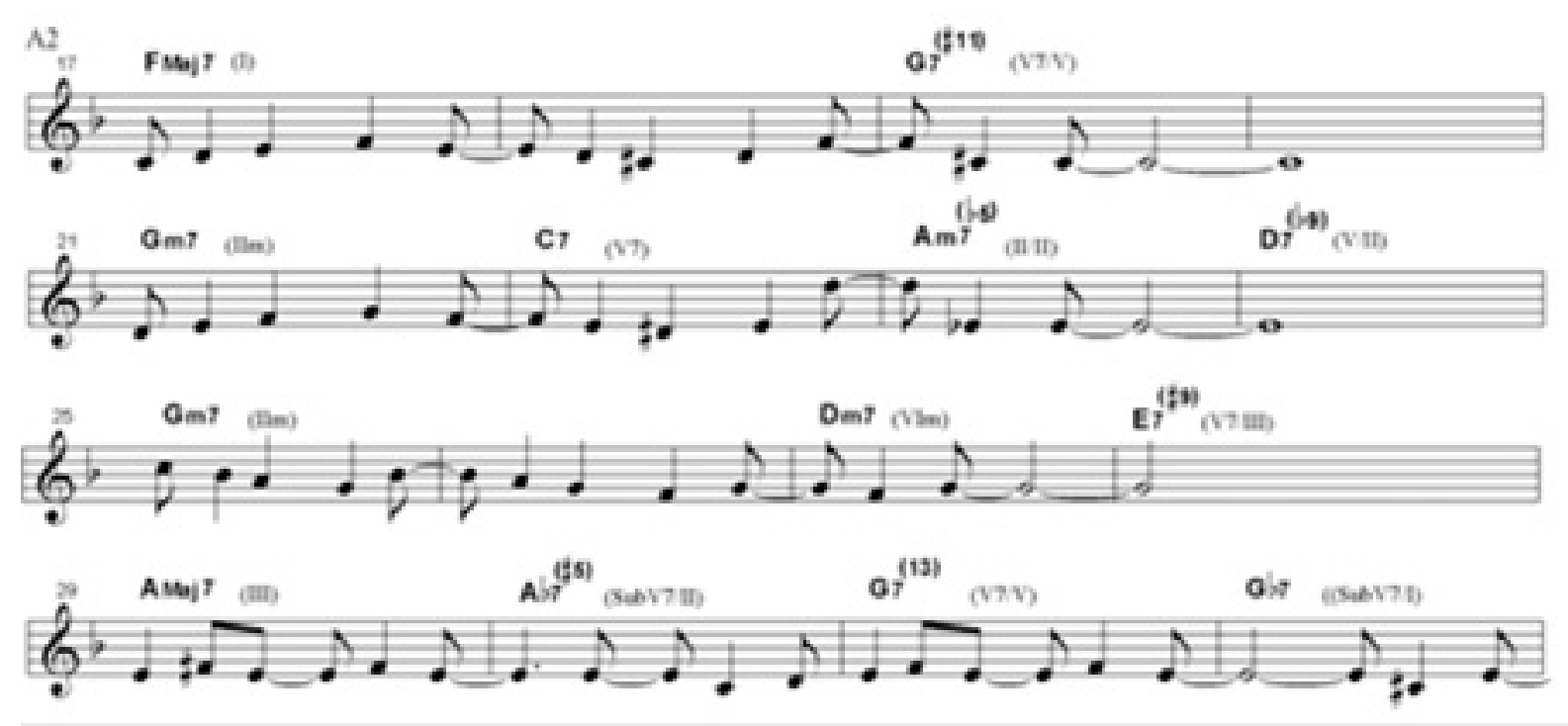

Figura 6: Songbook Tom Jobim, parte A2, c. 17-32.

$\mathrm{Na}$ exposição do primeiro tema (A1 compassos $01-16$ ), nas últimas duas notas da melodia do compasso 6 , há um intervalo melódico de uma sexta menor descendente entre as notas Mi e Dó, tendo na melodia a terça (nota Dó) do acorde Lá meio-diminuto. Já na $2^{\text {a }}$ vez em que esta melodia é apresentada, no compasso 22 há uma modificação da melodia e a última nota do compasso é a nota Ré, tendo um intervalo de sétima maior descendente, a $11^{\text {a }}$ de Lá meio-diminuto. Na versão de Jazz samba, não há essa modificação assim como os livros Real Book (manuscrito) e The New Real Book, cujas partituras possuem um ritornelo indicando o mesmo A. Outras gravações aqui citadas repetiram a versão de Jazz samba, as gravações de Sérgio Mendes e Bossa Rio, a de Ella Fitzgerald de 1962 (single) e no LP Ella abraça Jobim de 1981. Já neste trecho (c. 22-23) a cantora Pat Thomas canta como a versão original.

No compasso 28 João Gilberto executa ao violão o acorde Si diminuto (Bdim), um diminuto com função dominante $\left(E^{7}\right)$, e as partituras grafam como $E^{7(\# 9)}$, prevalecendo a função dominante do acorde diminuto. Na versão Sinatra-Jobim, no compasso 28 é tocado o acorde $\mathrm{E}^{7(\# 9)}$.

Uma outra diferença acontece nos compassos 29-32, no trecho em que a letra diz "isto é bossa nova, isto é muito natural". A versão de Jazz samba executa no $30^{\circ}$ compasso a nota Dó sustenido ao invés de Dó natural, desencadeando também uma outra harmonia, como mostra a Figura 7: 


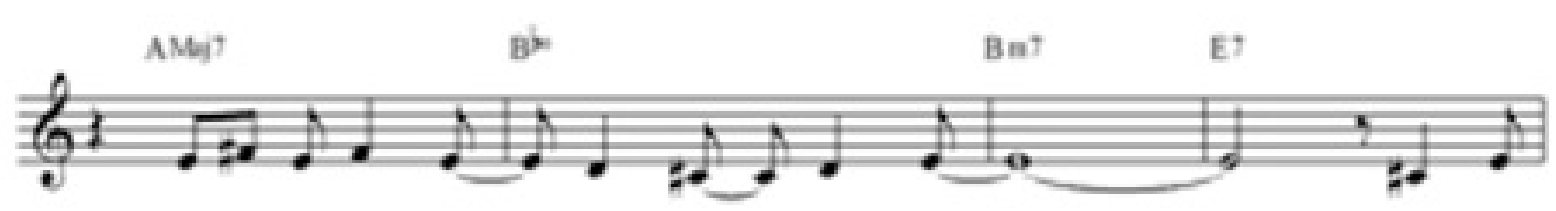

Figura 7: Jazz Samba. c. 29-32

A versão em Jazz samba acima (Figura 7) executa uma cadência autêntica $A$ - Bb$\operatorname{dim}-\mathrm{Bm}-\mathrm{E}^{7}\left(\mathrm{I}-\mathrm{V}^{7} / \mathrm{II}-\mathrm{IIm}^{7}-\mathrm{V}^{7}\right)$ muito diferente da versão original que contém uma progressão de acordes dominantes secundários substitutos descendentes que não irá se resolver, culminando na cadência de engano ( $\left.A^{7} M, A b^{7}, G^{7}, G b^{7}, A^{7} M\right)$. Para Gekas, após a resolução no acorde de $A^{7 M}(T)$ verifica-se uma sequência de dominantes substitutos que finaliza com o acorde de $\mathrm{Gb}^{7(\mathrm{~b} 13)}$. "Este acorde pode ser interpretado tanto como Dsub (dominante secundário) do sexto grau de Lá menor ou primeiro de Fá maior: $F^{7 M^{\prime \prime}}$ (Gekas, 2005, p. 99).

Na segunda parte da música (Figura 8), nos compassos 33-48, confirma-se a modulação de Fá para Lá.

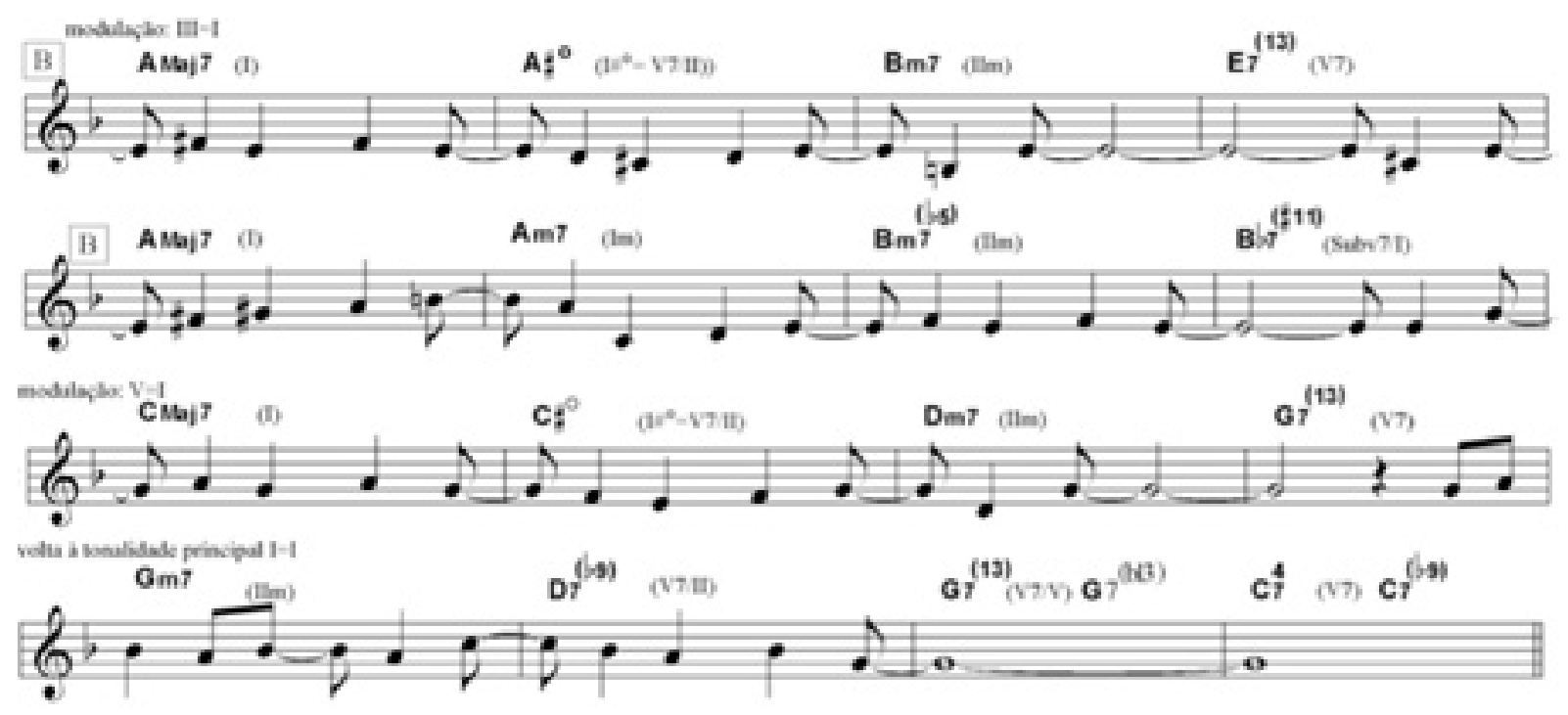

Figura 8: Songbook Tom Jobim, parte B, c. 33-48.

Na parte B surge um novo motivo em Lá (c. 33-40) que modula para Dó (c. 41-48) para finalmente alcançar a volta à parte A em Fá (c. 49-68) e novamente percebese algumas modificações melódico-harmônicas na versão Jazz samba, como nos compassos 37-40, em que a nota Dó natural é substituída pelo Dó sustenido no $38^{\circ}$ compasso, e o Fá natural na versão original de João Gilberto dá lugar a um Fá sustenido, modificando novamente a harmonia, como mostra o trecho a seguir: 


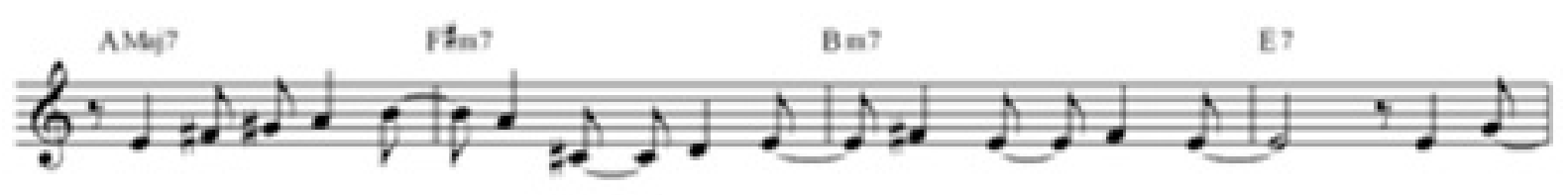

Figura 9: Jazz Samba. c. 37-40.

Na parte A3, volta-se para o tema inicial e finaliza-se a forma com 68 compassos, tendo o $A 3$ quatro compassos a mais do que as outras partes:

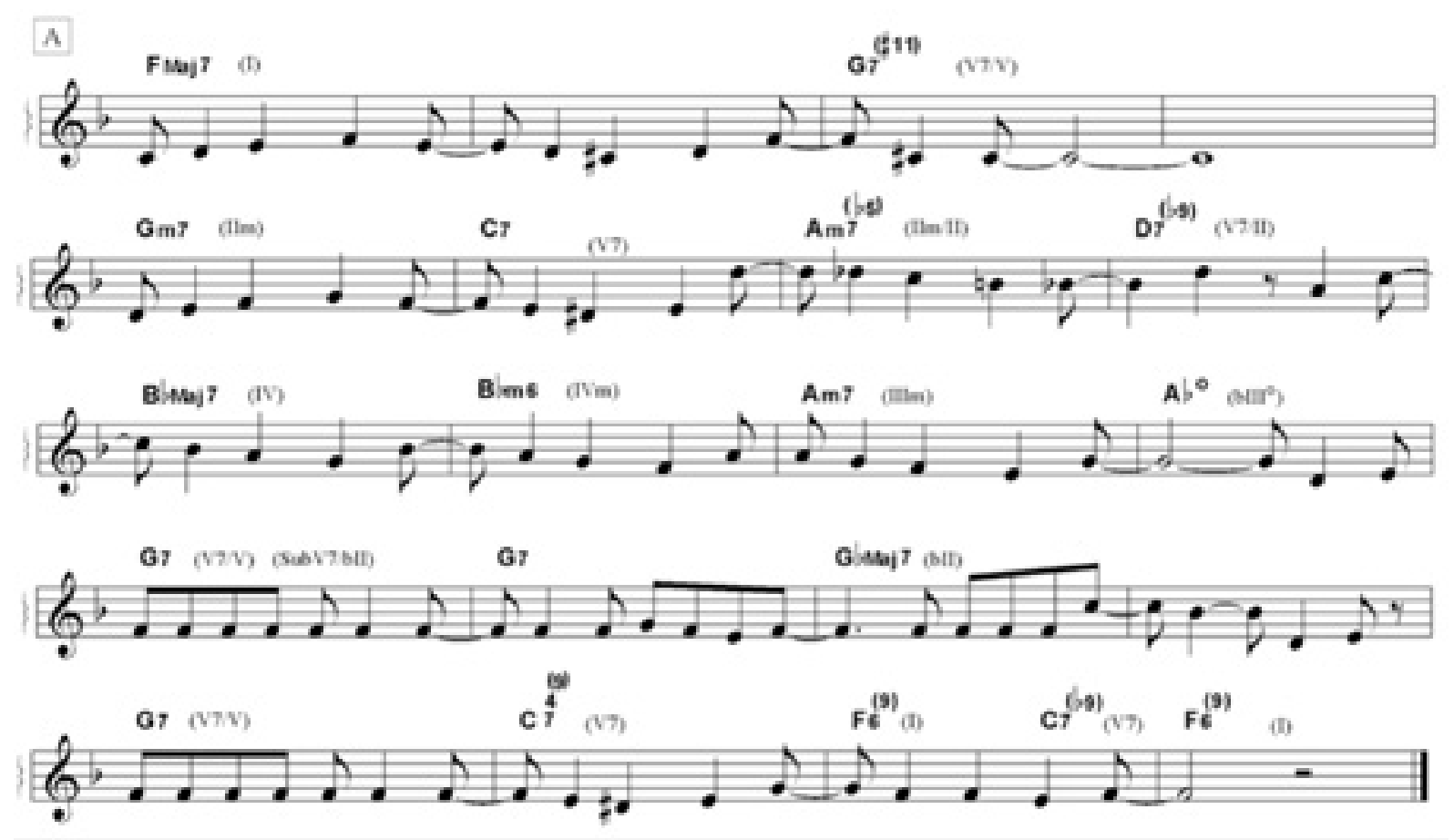

Figura 10: Songbook Tom Jobim, parte A3, c. 49-68.

No compasso 57, a versão Jazz Samba modifica a melodia original cantada por João Gilberto em Chega de saudade e o The Real book grafa como a versão Jazz Samba, como a Figura 11:

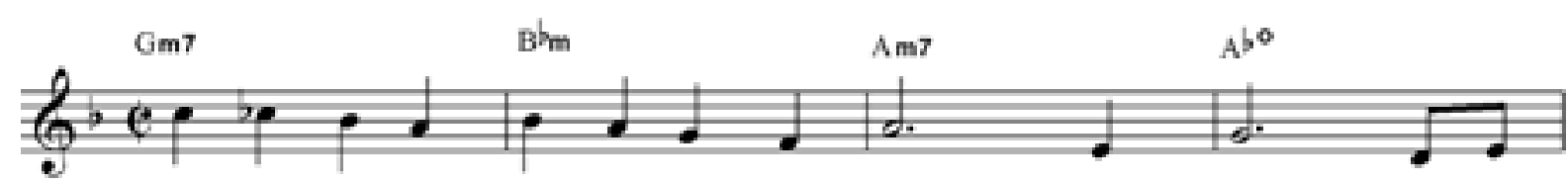

Figura 11: versões Jazz samba e The Real Book, c. 57-59.

Pode-se ainda observar no compasso 57 que em Jazz samba e nos dois realbooks americanos o acorde Gm7 (IIm) substitui $\mathrm{Bb}^{7 \mathrm{M}}$ (IV), e, embora haja mudança de acorde, a função subdominante prevalece. No compasso 59 o Songbook Tom Jobim grafa como Am7 (IIIm), João Gilberto em Chega de saudade executa F $7 \mathrm{M} / \mathrm{A}$, própria da linguagem violonística e Jazz samba executa $\mathrm{F}^{7 \mathrm{M}}$ (I), prevalecendo aqui 
a função tônica. Já no compasso 60, em que a melodia repousa na nota Sol, há várias versões de acordes, sendo Lá bemol diminuto ( $A b^{\operatorname{dim}}$ ) nos dois songbooks de Jobim, no The Real Book e em Sinatra/Jobim, Ré menor (Dm) em Chega de saudade, The composer of Desafinado plays e em Getz/Gilberto featuring A. C. Jobim e Sol dominante (G7) em Jazz Samba. Na partitura do The New Real Book 1 é grafado Ré menor (Dm) e o acorde G7 em parênteses.

Por fim, nos compassos 63-64, o acorde $\mathrm{Gb}^{7 \mathrm{M}}$, um acorde de empréstimo modal, extensão da subdominante menor Bbm, é executado nas quatro gravações em que Tom Jobim atua assim como nos songbooks brasileiros, entretanto, em Jazz Samba executa-se Bbm e nos livros The Real book e The New Real Book 1 estão grafados Bbm7 (c. 63) e Eb7 (c. 64). Observamos que nos compassos 63-64 da versão Getz/Gilberto a harmonia executa $\mathrm{Gb}^{7 \mathrm{M}}$ e o baixo $\mathrm{Eb}$, o que nos leva a entender que se possa pensar na harmonia $\mathrm{Eb}^{\text {sus7(9) }}$ ou Bbm7/Eb, também um acorde de empréstimo modal. Na versão de Pat Thomas no compasso 65 aparece Gm no lugar de G7.

Com relação às duas versões vocais, pudemos perceber que a versão da cantora Ella Fitzgerald de novembro de 1962 toma como base essa versão de Jazz Samba. Já a versão da cantora Pat Thomas, de setembro de 1962, considerada a primeira versão da música em língua inglesa, é mais fiel à versão brasileira de João Gilberto, contendo somente duas diferenças melódicas, na Figura 5 e na Figura 8, compasso 39, em que ela canta Fá sustenido, porém essa versão é pouco conhecida.

\section{Considerações finais}

Analisamos as gravações de "Desafinado" em Chega de saudade (1959), em Jazz samba (1962), em The composer of Desafinado plays (1963), em Getz/Gilberto featuring A. C. Jobim (1963) e em Sinatra/Jobim e as partituras dos livros The Real book (1971), The New Real Book 1 (1995), Songbook Tom Jobim (1994), Cancioneiro Jobim (2001). Temos, portanto, cinco versões da música, sendo quatro delas com um dos autores da música (Tom Jobim) atuando como arranjador e/ou intérprete. Percebemos que houve consenso quando Jobim participou das quatro versões, pois houve somente uma diferença melódico-harmônica na versão Sinatra/Jobim nos compassos 29-30 (Figura 7) com relação às outras versões. 
A versão de Jazz samba, por outro lado, possui várias alterações melódico-harmônicas, mas alcançou o mercado internacional mais rapidamente que as outras versões. As partituras de "Desafinado" transcritas no The Real Book (manuscrito) e no The New Real Book 1 estão na tonalidade de Fá maior e possuem as mesmas modificações melódico-harmônicas da versão Jazz samba apontadas neste estudo. Percebe-se, portanto, que nos livros estrangeiros prevaleceu a versão de Jazz Samba. A versão da canção discutida na dissertação de José Estevam Gava (UNESP, 1994) e vertida no livro A linguagem harmônica da Bossa Nova (Ed. UNESP, 2008) também leva em consideração a versão de Jazz Samba.

Jazz samba é de 1962. É relevante, portanto, que se observe que a primeira gravação de "Desafinado" foi a de João Gilberto de 1959, e, apesar do disco Getz/ Gilberto featuring A. C. Jobim ter sido lançado em 1964 e alcançado inúmeros prêmios, a versão de "Desafinado" transcrita nos dois livros Real Book é a de Jazz Samba. Muitas outras gravações e publicações de partituras têm sido lançadas, disseminando diferentes versões para essa composição, interferindo sobremaneira nas execuções posteriores dessa canção.

As cinco versões da canção "Desafinado" aqui discutidas são de grande valor artístico. João Gilberto trouxe o diálogo entre voz e violão, Stan Getz e Charlie Byrd, a improvisação jazzística, Tom Jobim apresenta uma versão instrumental tendo o piano como melodista, Gilberto e Getz uma parceria que transcendeu as fronteiras do jazz e, finalmente, Sinatra e Jobim, que uniu o cantor mais popular da época com o grande compositor brasileiro.

A bossa nova abriu novos campos estéticos para a nossa cultura e impôs um novo olhar para música popular brasileira, conquistando grande visibilidade ao ser assimilada e difundida por artistas de todo o mundo. Que nossa música possa ser interpretada, impressa, revisada e divulgada em todo o mundo e que os músicos se encorajem em conhecer e transcrever as primeiras versões de discos históricos para que se conheçam e, sobretudo, que se executem versões originais de músicas brasileiras. Afinal, para um músico, educador e pesquisador musical, expressar-se na música, sobre e diante dela, deve ser entendido também como um resgate da própria cultura. 


\section{Referências}

AURWIN, Nicholas; The Jazz Sippers Group. The history of Jazz and the Jazz Musicians. Lulu Press Inc. 2009. (E-book).

Billboard Music Week. Hot 100. 15 dez. 1962. Disponível em: <https://books. google.com.br/books?id=KRgEAAAAMBAJ\&pg=PP4\&dq=desafinado++billboard+getz+pat+ella\&hl=pt-BR\&sa =X\&ved=0ahUKEwjB9qCAkoDOAhWEQpAKHV47DfMQ6AEIJjAB\#v=onepage \&q=desafinado\%20\%20billboard\%20getz $\% 20$ pat $\% 20$ ella\&f=false $>$. Acesso em: 17 mar. 2016.

BOLLOS, Liliana Harb. Bossa nova e Crítica: polifonia de vozes na imprensa. São Paulo: Annablume/FUNARTE, 2010.

. A bossa nova no exterior: duas versões de Desafinado. Anais do V Simpósio Internacional de Musicologia, Escola de Música e Artes Cênicas da Universidade Federal de Goiás, Pirenópolis, p.77-83, 2015. Disponível em: <http://media.wix. com/ugd/c1b035_11ed326d20914d04b772b5f0ad50bade.pdf $>$. Acesso em: 26 maio 2016.

BRITO, Brasil Rocha. Bossa nova. 1960. In: CAMPOS, Augusto de. Balanço da bossa. São Paulo: Perspectiva, 1993.

CÂMARA, Marcelo. Caminhos cruzados: a vida e a música de Newton Mendonça. Rio de Janeiro: Mauad, 2001.

CARDOSO, Elizete. Canção do amor demais. Rio de Janeiro, Festa, FT 1801, 1958. $1 \mathrm{CD}$.

CASTRO, Ruy. Chega de saudade: a história e as histórias da Bossa Nova. 3. ed. São Paulo: Companhia das Letras, 2002.

FITZGERALD, Ella. Desafinado (Slightly out of tune). Los Angeles, Verve Records, VK10274, 1962. 1 Single.

HUNGRIA, Júlio. No caminho do Carnegie Hall. Correio da Manhã, 28 nov. 1962. 2. Caderno, p. 1.

GAVA, José Estevam. A linguagem harmônica da Bossa Nova. 2. ed. São Paulo: Ed. Unesp, 2008. p.126-129.

GEKAS, Paulo Demetre. Correlações entre Desafinado e Moon dreams: uma análise dos processos lineares e harmônicos. Dissertação (Mestrado em Educação e Cultura) - Universidade do Estado de Santa Catarina, Santa Catarina, 2005.

GETZ, Stan; BYRD, Charlie. Jazz samba. Verve. EUA. V6-8432. 1962. 1 CD.

GETZ, Stan; GILBERTO, João. Getz/ Gilberto featuring A. C. Jobim. Verve 314521414, 1964. New York. 1 CD. 
GILBERTO, João. Chega de saudade. Rio de Janeiro, EMI-Odeon 3073, 1959. 1 CD.

GOLD, Michael; VILLA, Dario. Tradings fours: Jazz and the learning organization. Milano: Art for Business Edizioni, 2012.

HAWKINS, Coleman. Desafinado. Impulse. A28. 1962.

JOBIM, Antônio Carlos. Entrevista. In: Songbook Tom Jobim. v. 2. Rio de Janeiro: Lumiar, 1994. p.16-18.

. Cancioneiro Jobim. Rio de Janeiro: Jobim Music, 2001.

Songbook Tom Jobim. v. 3. Rio de Janeiro: Lumiar, 1994. p. 39-41.

LEONARD, Hall (Ed.). The real book. Milwaukee, WI: Hal Leonard, 2004.

MATTOS, Flávio de. O Desafinado sucesso da Bossa Nova de Charlie Byrd e Stan Getz em Jazz Samba. O Globo, Blog do Noblat. Disponível em: <http://noblat. oglobo.globo.com/artigos/noticia/2016/08/o-desafinado-sucesso-da-bossa-novade-charlie-byrd-e-stan-getz-em-jazz-samba.html>.

MELLO, Zuza Homem de. João Gilberto. São Paulo: Publifolha, 2001.

MORAES, Vinicius de. Bossa nova em tom bem triste. Diário Carioca, Rio de Janeiro, 12 nov. 196.

NAVES, Santuza Cambraia. A canção popular entre a biblioteca e a rua. In: Decantando a república: outras conversas sobre os jeitos da canção. Rio de Janeiro: Nova Fronteira, 2004. p. 79-96.

PEKAR, Harvey. Revista Down Beat. v. 30, n. 2, 17 jan. 1963.

Sinatra/Jobim. The Complete Reprise Studio Recordings. Los Angeles: Reprise, 1995. 1 CD.

SHER, Chuck (Org.). The New Real Book 1. Petaluma, EUA: Sher Music Co., 1995. p. 65-66.

The Real Book (manuscrito). 1971, p. 112-113. [s.n.](Partitura).

THOMAS, Pat. Desafinado. Nova York: Verve. VK-10269. Disponível em: <https:// www.youtube.com/watch?v=nrdzKBOr_HE>. Acesso em: 15 jun. 2016.

VASCONCELOS, Ary. Panorama da música popular brasileira. Vol. 1. Rio de Janeiro: Martins, 1964. 